\title{
Terminologia do Licenciamento Ambiental Brasileiro em Português e Inglês
}

\section{Terminology of the Brazilian Environmental Licensing in Portuguese and in English}

\section{Caroline Lúcia Costa Moia Chichorro* Patrícia Chittoni Ramos Reuillard ${ }^{\star *}$}

Resumo: Esta pesquisa objetivou repertoriar os termos do licenciamento ambiental brasileiro e oferecer seus equivalentes em língua inglesa. Foram utilizados dois corpora, nos idiomas português e inglês. Baseia-se nos pressupostos da Teoria Comunicativa da Terminologia (CABRÉ 1999a), da Linguística de Corpus (SARDINHA 2004) e no conceito de equivalência funcional (GÉMAR 1998; ŠARČEVIĆ 1997). Os corpora foram analisados com o programa AntConc (ANTHONY 2014), com apoio da árvore de domínio e dos fluxogramas do licenciamento ambiental elaborados. Foram validados 371 termos do domínio do licenciamento ambiental. Dadas as diferenças jurídicas e culturais existentes entre as línguas selecionadas, evidenciadas na terminologia estudada, observou-se não ser possível oferecer um equivalente funcional para todos os termos repertoriados, reforçando a necessidade em prosseguir com a pesquisa.

Palavras-chave: Terminologia; Licenciamento Ambiental; Equivalência Funcional.

\footnotetext{
* Analista de Meio Ambiente da Secretaria de Estado de Meio Ambiente de Mato Grosso, Mestre pelo Programa de Pós-Graduação em Letras da Universidade Federal do Rio Grande do Sul (UFRGS). E-mail: carol_chichorro@yahoo.com.br.

"* Professora do Departamento de Línguas Modernas e do Programa de Pós-Graduação do Instituto de Letras da Universidade Federal do Rio Grande do Sul (UFRGS); tradutora de língua francesa. E-mail: patrícia.ramos@ufrgs.br.
} 
Abstract: This research aimed to collect the terms of the Brazilian environmental licensing and offer their equivalents in English. We used two corpora, in Portuguese and in English. It is based on the assumptions of the Communicative Terminology Theory (CABRÉ 1999a), of Corpus Linguistics (SARDINHA 2004) and on the concept of functional equivalence (GÉMAR 1998; ŠARČEVIĆ 1997). We analyzed corpora with AntConc program (ANTHONY 2014), and the support of the domain tree and the environmental licensing flowcharts developed. We validated 371 terms of the environmental licensing domain. Given the legal and cultural differences between the selected languages, evidenced in the terminology studied, it was not possible to offer a functional equivalent for all terms, reinforcing the need to continue the research.

Keywords: Terminology; Environmental Licensing; Functional Equivalence.

\section{Introdução}

Este artigo é uma síntese da dissertação de Mestrado em Teorias Linguísticas do Léxico, apresentada como requisito parcial para a obtenção do título de Mestre pelo Programa de Pós-Graduação em Letras da Universidade Federal do Rio Grande do Sul em março de 2016 (CHICHORRO 2016).

Licenciar um empreendimento ou atividade é competência dos órgãos ambientais das três esferas de poder (federal, estadual e municipal). Cabe, então, aos servidores dessas instituições, acolher e orientar empreendedores sobre documentos e procedimentos necessários para a obtenção das licenças. No entanto, o Licenciamento Ambiental brasileiro constitui instrumento de proteção ambiental bastante complexo, dividido em três fases, de modo que, se para um falante de português do Brasil compreender tal instrumento para poder agir conforme a lei não é tarefa fácil, para um estrangeiro a situação

pode ser ainda mais difícil em decorrência das diferenças linguísticas e culturais. 
Nossa experiência como analista da Secretaria de Estado de Meio Ambiente de Mato Grosso (SEMA-MT) nos proporciona participar de reuniões com comitivas internacionais de diferentes composições (empresários, ambientalistas, políticos, jornalistas, etc.) em busca de informações sobre o licenciamento ambiental; nesses momentos, percebemos dificuldades na comunicação entre brasileiros e estrangeiros. 0 idioma normalmente utilizado nessas interações é o inglês, considerado o principal idioma nas comunicações internacionais (SСHüTZ 2010). Observamos que essa dificuldade de comunicação atinge também os tradutores, quando se fazem presentes, e que decorre tanto da complexidade do tema, quanto do uso de diversos termos técnicos.

Sendo a Terminologia a disciplina linguística dedicada ao estudo científico dos conceitos e termos usados nas linguagens de especialidade (PAVEL; Nolet 2002), acreditamos que um estudo terminológico que ofereça os termos do licenciamento ambiental brasileiro com seus respectivos equivalentes em língua inglesa poderá auxiliar os servidores dos órgãos ambientais, bem como os tradutores, na missão de transmitir informações e orientar os interessados estrangeiros acerca das licenças, documentos e procedimentos envolvidos no licenciamento.

Assim, a partir da constatação das dificuldades de comunicação entre os servidores dos órgãos ambientais licenciadores e os interessados estrangeiros, citadas anteriormente, nossa pesquisa teve por objetivo geral repertoriar os termos mais relevantes do licenciamento ambiental brasileiro, com vistas à elaboração futura de um glossário sobre o tema.

Para elaborar esse repertório, primeiramente delimitamos e descrevemos o licenciamento ambiental brasileiro de modo a auxiliar a identificação da terminologia da área; em seguida, estabelecemos os passos metodológicos e selecionamos os termos dessa temática; por fim, procuramos propor equivalentes em inglês para os termos arrolados em português.

\section{O Licenciamento Ambiental Brasileiro}


Estabelecido pela Lei n. ${ }^{\circ}$ 6.938, de 31 de agosto de 1981, popularmente conhecida por Política Nacional do Meio Ambiente - PNMA, o licenciamento é regulamentado pela Resolução do Conselho Nacional do Meio Ambiente - CONAMA n. ${ }^{\circ} 237 / 1997$, que o define como:

[...] o procedimento administrativo pelo qual o órgão ambiental competente licencia a localização, instalação, ampliação e operação de empreendimentos e atividades utilizadoras de recursos ambientais consideradas efetiva ou potencialmente poluidoras ou daquelas que, sob qualquer forma, possam causar degradação ambiental, considerando as disposições legais e regulamentares e as normas técnicas aplicáveis ao caso. (BRASIL 1981)

Trata-se de um instrumento de gestão ambiental considerado complexo por ser composto por três diferentes etapas, sendo necessária, desde a aprovação de um projeto de empreendimento até a sua operação efetiva, a expedição de três licenças pelo Poder Público. Assim, para concluir o licenciamento, é necessário que se cumpram três fases, com a obtenção de suas respectivas licenças: Licença Prévia (LP), Licença de Instalação (LI) e Licença de Operação (LO).

Além de possibilitar agir preventivamente sobre a proteção do meio ambiente na tentativa de compatibilizar sua preservação com 0 desenvolvimento econômico-social, o licenciamento ambiental é considerado condição essencial para se obter financiamento junto a instituições financeiras, bem como para conseguir incentivos governamentais para um empreendimento. Dessa forma, após a instituição desse instrumento da política ambiental, a preservação ambiental passou a ser condição ao desenvolvimento econômico, estando este atrelado ao licenciamento ambiental.

Há que se dizer, ainda, que a ausência das licenças ambientais referentes às diferentes fases do licenciamento configura crime, conforme disposto na Lei de Crimes Ambientais (n. ${ }^{\circ}$ 9.605, de 1998) e pode acarretar em pena de um a seis meses, ou multa, ou ambas, cumulativamente, aos empreendedores, na ocorrência de construção, reforma, ampliação, instalação ou funcionamento de estabelecimentos, obras ou serviços potencialmente poluidores.

Neste contexto, em nossa experiência enquanto analista ambiental da SEMA-MT, observamos a alta complexidade inerente ao licenciamento TradTerm, São Paulo, v. 32, dezembro/2018, p. 52-90 
ambiental. Ademais, notamos que o cidadão que procura a secretaria nem sempre conhece os conceitos que a atividade engloba, presentes na documentação exigida e nos procedimentos necessários para a obtenção das licenças ambientais. Essa complexidade, aliada ao desconhecimento dos conceitos, causa, muitas vezes, dificuldades na comunicação entre os analistas ambientais e os empreendedores ou estudiosos e ambientalistas que buscam a Secretaria visando conhecer o licenciamento ambiental ou regularizar ambientalmente suas atividades econômicas, principalmente se essa interação envolver um público estrangeiro.

Por essa razão, julgamos necessário oferecer aos empreendedores conhecimento acerca dos atores, etapas, procedimentos e documentação envolvidos no licenciamento ambiental, permitindo que a comunicação entre eles e os especialistas em meio ambiente, neste caso mais especificamente em licenciamento ambiental, seja exitosa. Na ausência de uma obra terminológica voltada especificamente à atividade do licenciamento ambiental, almejamos favorecer a comunicação entre as partes a partir do reconhecimento e compilação da terminologia da área, além de procurar propor os respectivos equivalentes em língua inglesa.

\section{Pressupostos teóricos}

A pesquisa foi construída com base nos pressupostos da teoria Comunicativa da Terminologia - TCT, da Linguística de Corpus e no conceito de equivalência funcional originado dos estudos de tradução jurídica, sobre os quais discorremos abaixo.

\subsection{A Teoria Comunicativa da Terminologia - TCT}

Diferentes teorias de Terminologia adotam posições distintas quanto à compreensão dos termos ou à metodologia de trabalho. Para esta pesquisa 
escolhemos seguir os princípios da Teoria Comunicativa da Terminologia, a qual compreende a Terminologia como:

“uma matéria de caráter interdisciplinar, integrada por fundamentos
procedentes das ciências da linguagem, das ciências da cognição e
das ciências sociais. Estes três fundamentos inspiram, por sua vez, a
poliedricidade da unidade terminológica, que é, ao mesmo tempo,
uma unidade linguística, cognitiva e sociocultural" (CABRÉ 1999b:
70).

Desta forma, a teoria fundamenta-se sobre um tripé teórico constituído pelas teorias: da linguagem, para dar conta do estudo das unidades terminológicas pelo viés linguístico; do conhecimento, relacionada ao estudo dos conceitos e das relações conceito-designação; e da comunicação, dedicada ao estudo das situações comunicativas onde os termos se apresentam (CABRÉ 1999b: 124). Os termos podem, em decorrência dessa fundamentação, ser analisados de três perspectivas diferentes: linguística, cognitiva e comunicativa.

Segundo esta teoria, a Terminologia tem por objetivo descrever a unidade terminológica em seus aspectos formais, semânticos e funcionais, de modo a dar conta de como o valor de termo é ativado, explicando, ainda, sua relação com outros signos, visando ampliar o conhecimento sobre a comunicação especializada e as unidades nela utilizadas (CABRÉ 1999b: 133). Ao se propor tal objetivo, compreende-se que a função do trabalho terminológico não se restringe a prescrever e normalizar, pois o estudo descritivo, conforme proposto pela TCT, amplia os horizontes da disciplina.

$\mathrm{O}$ aspecto teórico de maior relevância trazido pela TCT é o que diz respeito ao modo como esta teoria concebe o termo técnico e científico. Apesar de vincularem um conhecimento especializado, os termos são unidades lexicais das línguas naturais, possuindo as mesmas características formais, semânticas e funcionais destas (CABRÉ 1999a: 80).

Destacamos o aspecto pragmático dos termos, tendo em vista que são unidades do léxico comum que adquirem estatuto de termo nas comunicações especializadas, ou seja, tornam-se termos em um contexto expressivo e comunicacional específico (CABRÉ 1999a: 36). O termo científico pode ser abordado por diferentes âmbitos e perspectivas, e, por não constituírem um 
sistema independente das palavras, mas, ao contrário, compartilharem características e comportamentos do léxico comum, estão sujeitos a eventos como analogia, empréstimo, sinonímia e polissemia.

Assim, é abandonada a crença de que os termos pertencem a um domínio exclusivamente, admitindo-se que eles são, na verdade, "usados em um domínio com um valor singularmente específico" (CABRÉ 1999b: 124, tradução nossa ${ }^{1}$ ). Podemos exemplificar tal afirmação com o emprego do termo sal nos domínios da química e da culinária. Para a química, o termo sal poderia ser definido como: “Composto que resulta da ação dos ácidos sobre as bases; composto resultante da substituição de um metal pelo hidrogênio básico dos ácidos" (“SAL”, 2009-2018). No entanto, o mesmo termo, para a culinária, pode ser definido como: "Substância seca, dura, friável, de sabor acre, solúvel na água e que, ordinariamente, se emprega como tempero; cloreto de sódio" ("sal”, Dicionário Online de Português). Como consequência, variação linguística, polissemia, homonímia e sinonímia passam a ser aceitas e tratadas em estudos terminológicos guiados pela TCT.

Quanto à metodologia de trabalho, destaca-se a flexibilidade dada pelo Princípio de Adequação, segundo o qual, em linhas gerais, a metodologia não deve ser imposta, mas adequada à temática, ao contexto, aos elementos implicados e aos recursos disponíveis para o trabalho terminológico. Desse modo, pode-se adotar uma perspectiva onomasiológica ou semasiológica; utilizar textos ou bancos de dados; propor a normalização dos termos de uma área ou apenas compilá-los, sem que os princípios teóricos sejam contrariados (CABRÉ 1999b: 137).

Segundo a classificação elaborada por Cabré (1999b: 130), considera-se a pesquisa terminológica ora proposta como semasiológica, pois busca repertoriar os termos de uma área de especialidade, o licenciamento ambiental, partindo do termo aos conceitos. Para esse tipo de pesquisa, Sager (1990: 134), Cabré (1999b: 164) e Barros (2004: 264) apontam as vantagens do uso de corpora e ferramentas computacionais para o processamento dos dados, entre as quais se destacam: a maior precisão e praticidade conferida aos estudos; a grande quantidade de dados linguísticos disponíveis para

\footnotetext{
${ }^{1}$ Los términos no pertenecen a un ámbito sino que son usados en un ámbito con un valor singularmente específico (grifos do autor).
}

TradTerm, São Paulo, v. 32, dezembro/2018, p. 52-90

www.revistas.usp.br/tradterm 
fundamentar as decisões do terminólogo; e a produção de evidências documentais para as informações elencadas na ficha terminológica.

Quanto à rotina do trabalho terminográfico, é consenso entre os autores Cabré (1999b: 130), Krieger e Finatto (2004: p. 134), Barros (2004: 189) e Bevilacqua (no prelo), a necessidade de seguir algumas etapas básicas, que podem ser organizadas em etapas prévias e etapas de pesquisa. Sobressaem-se das etapas prévias a definição e delimitação do que será feito, identificando-se aspectos primordiais como a área de especialidade, 0 público-alvo, os objetivos e a função da obra pretendida; a preparação da pesquisa, a construção de um corpus, a elaboração da árvore de domínio, a identificação dos termos e extração de informações linguísticas do corpus.

\subsection{A pesquisa terminológica associada à linguística de corpus}

Pelo fato de essa pesquisa se basear no estudo de dois corpora, um em língua portuguesa, na variante brasileira, outro em língua inglesa, variante norte-americana, ambos compostos por 41 textos - legislações voltadas à regulamentação do licenciamento ambiental e manuais de orientação cujo público-alvo são os empreendedores -, recorremos também aos pressupostos da Linguística de Corpus.

Definida como uma "abordagem que se ocupa da coleta e exploração de corpora, ou conjuntos de dados linguísticos textuais (...) coletados criteriosamente, com o propósito de servirem para a pesquisa de uma língua ou variedade linguística" (SARDINHA 2004: 18), a Linguística de Corpus proporciona à Terminologia um novo método de trabalho.

0 uso de ferramentas informáticas e a possibilidade de explorar grandes conjuntos de textos tornam possível a observação dos fenômenos linguísticos em situações reais de uso, de modo que as pesquisas passam a contar com dados empíricos. Conforme pontua Maciel (2006: 4), "a evidência empírica mostra aspectos inesperados, na medida em que a língua aparece em 
exemplos isolados ou em grandes blocos de textos", proporcionando aos linguistas a possibilidade de compreender melhor o funcionamento das línguas, visto que as análises passam a ser baseadas em amostras representativas e abundantes de produções linguísticas (CABRÉ, 1999b: 164).

Deste modo, ao proporcionar a observação dos termos nos textos de especialidade, o uso de corpora, nos estudos terminológicos, favorece as pesquisas fundamentadas na TCT, a qual postula que as unidades lexicais de uma língua não são, de início, nem termos nem palavras, e que o caráter terminológico é ativado no texto, determinado pelo uso em contexto e situação adequados. A pesquisa em corpora permite analisar o termo para além da unidade, observando os contextos linguísticos e pragmáticos, que determinarão se a unidade analisada terá ou não valor de termo (KRIEGER; FINATTO 2004: 78), a saber: "unidade lexical especializada que tem como função primordial expressar o conhecimento de caráter científico, técnico e tecnológico e como missão paralela transferir o conhecimento veiculado pela comunicação humana" (KRIEGER; MACIEL 2001: 66).

Segundo Finatto (2004: 98):

a Lingüística de Corpus (doravante LC) ocupa-se da exploração de grandes extensões de corpora textuais em formato digital que são "minerados" com apoio informatizado, com destaque para as explorações estatísticas de elementos lexicais e observação das frequiências de combinatórias de palavras, [...].

Desta forma, esta pesquisa se apoiou na Linguística de Corpus para a construção de sua metodologia de investigação, observando orientações para a compilação e a análise dos corpora utilizados, podendo ser considerada uma pesquisa linguística baseada em corpus.

\subsection{Equivalência Funcional}

Considerando que um dos objetivos da pesquisa é procurar oferecer equivalentes, em inglês, aos termos do licenciamento ambiental encontrados em português, o conceito de equivalência revela-se incontornável. A busca 
por equivalentes em inglês para os termos do licenciamento ambiental brasileiro, matéria tratada no âmbito do Direito Ambiental, está, neste trabalho, fundamentada nos estudos de tradução jurídica.

Por ser imbuída da cultura, conforme afirma Gémar (1998), além de apresentar uma terminologia específica, a linguagem do Direito inclui palavras da língua geral, cujos sentidos, conotações, valores e particularidades semânticas atualizados em contexto resultam da tradição cultural. Os termos advindos da língua geral podem, da mesma forma que aqueles próprios ao domínio, sofrer alterações efetivas de significado quando adotados ou utilizados em um sistema jurídico diferente.

o Direito impõe à língua e, consequentemente, ao tradutor, suas próprias restrições terminológicas e estilísticas: "Se é difícil se entender em relação ao sentido e à significação das palavras dentro de uma só língua, pode-se imaginar facilmente a dificuldade criada pela comparação entre línguas, de um lado, e entre sistemas, de outro" (GÉMAR 1998: 7),

Devido às restrições impostas pelo Direito e sua linguagem, em se tratando de tradução de textos jurídicos, a igualdade de significados pode não ser sempre alcançada na prática, especialmente se o texto tiver força de lei também na língua de chegada. Como já apontamos, o texto jurídico pode implicar efeitos jurídicos. Assim, o principal objetivo do tradutor jurídico não deve se resumir a produzir um texto meta cujo significado seja igual ao da mensagem do texto fonte. Sua tarefa consiste, principalmente, em fornecer um texto que reproduza os mesmos efeitos jurídicos e que tenha a mesma significação legal (HERBOTS 1987 apud (ŠARČEVIĆ 1997). Embora, muitas vezes, a tradução possa ter caráter apenas informativo, o uso de um termo inadequado ao contexto pode acarretar efeitos diferentes, induzindo o leitor ao erro. Podemos exemplificar tal problema com o adjetivo equitable, muito presente no sistema jurídico inglês (Common Law). Déborah Cao (2007: 61, tradução nossa) explica que, a um tradutor sem experiência em tradução jurídica, o referido adjetivo pode parecer uma palavra comum em detrimento do efeito legal que carrega.

O eqüitativo, nesse sentido, carrega significados jurídicos substanciais que vão muito além do significado literal de ser justo, 
correto ou equitativo. Refere-se ao corpo de princípios jurídicos únicos na tradição jurídica inglesa.

A autora afirma que não há um equivalente exato para o termo no sistema Civil Law e que são necessários, ao tradutor jurídico, conhecimento básico dos sistemas jurídicos relevantes e suas estruturas, bem como um alto grau de proficiência no par de línguas em questão.

A autora (ŠARČEVIĆ 1997) aponta que o significado dos textos jurídicos é determinado pelo contexto jurídico e não apenas por aspectos linguísticos. Significado e efeito jurídico estão, por sua vez, subordinados à intenção, que, em sua forma macro, refere-se à função comunicativa do texto, e, em sua forma micro, relaciona-se às intenções do autor com aquele texto.

Com base nas particularidades apontadas a respeito do texto jurídico, Garzone (2000: 9) afirma que:

O uso de uma abordagem funcional parece ser especialmente adequado à tradução de textos jurídicos, [...] embora não dê conta da questão de equivalência, a situa de maneira diferenciada, [...] traz a noção de que o grau de equivalência a ser alcançado em uma tradução não é absoluto, e depende, primeiro e acima de tudo, da função do texto meta bem como da natureza do texto fonte $[\ldots]^{2}$

Consequentemente, para que a tradução jurídica seja eficaz, a busca por equivalência, "maior correspondência possível entre o texto fonte e o texto meta” (NORD 1991: 22, tradução nossa ${ }^{3}$ ), "não deve ser reduzida ao processo de equiparar “equivalentes”” (ŠARČEVIĆ 1997: 229, tradução nossa, grifo da autora), mesmo em um trabalho de equivalência terminológica. A escolha de um equivalente deve levar em conta o processo de comunicação, a situação comunicativa de recepção e, principalmente, neste caso, os efeitos legais e práticos de cada escolha.

Como os pontos de vista sobre a equivalência variam conforme as abordagens dos estudiosos da tradução, seguimos as orientações de Gémar (1998), que trabalha a tradução jurídica a partir da noção de equivalência

\footnotetext{
${ }^{2}[\ldots .$.$] the application of a functional approach seems especially suitable for the translation of$ legal texts, [...] although it does not circumvent the problem of equivalence, but rather poses it in different terms [...] it brings home the notion that the degree of equivalence to be achieved in the translation of a given text is not absolute, but depends first and foremost on the TT intended function as well as on the nature of the ST [...].

${ }^{3}[. .$.$] the greatest possible correspondence between source text and target text.$
}

TradTerm, São Paulo, v. 32, dezembro/2018, p. 52-90

www.revistas.usp.br/tradterm 
funcional: uma estrutura do texto de chegada deve expressar a mesma relação semântica e o mesmo efeito pragmático de determinada unidade do texto de partida. Seria necessário, então, conseguir expressar a mensagem do texto de partida no contexto do texto de chegada (efeito pragmático), sem que se perca o efeito jurídico, resultado prático decorrente da aplicação do direito em casos concretos (caso do adjetivo equitable citado).

Em seus estudos, Šarčević (1997: 236, tradução nossa ${ }^{4}$ ) também se serve desse conceito e o define como a escolha de "um termo que designa um conceito ou instituição do sistema jurídico meta que tenha a mesma função que um determinado conceito do sistema jurídico fonte". Embora não se valham das mesmas palavras para explicar a equivalência funcional, cremos que a ideia principal dos autores é de encontrar unidades lexicais que, "em uma situação de assimetria, permitam ao texto meta funcionar ou ter uma utilidade, uma finalidade prática na cultura receptora da tradução" (CHANUT 2012: 48).

Entre o par de línguas escolhido para esta pesquisa, português ( $\mathrm{PtBr}$ ) inglês (EnAm), tal noção pode ser exemplificada com o termo Ministro da Justiça e seu equivalente funcional Attorney General. Os termos se equivalem quanto à ordem hierárquica dos cargos. Porém, quanto à função exercida, um Attorney General desempenha atividades que, no Brasil, não cabem apenas ao Ministro da Justiça, sendo realizadas também pelo Procurador Geral da República. Não há, portanto, uma correspondência total dos termos. A correspondência é apenas parcial. Em outro exemplo, o equivalente funcional da expressão Conselho de Ministros é Cabinet, e não Council of Ministers, pois Council of Ministers não corresponde a nenhum conceito no sistema jurídico inglês (GUDUMAC 2001).

Considerando as diferenças culturais existentes entre Brasil e Estados Unidos e as implicações que tais diferenças podem ter sobre o licenciamento ambiental, a realização deste estudo demandou o embasamento nos conceitos de equivalência funcional oferecidos por Šarčević (1997) e Gémar (1998).

\footnotetext{
${ }^{4}[\ldots]$ a term designating a concept or institution of the target legal system having the same function as a particular concept of the source legal system.
}

TradTerm, São Paulo, v. 32, dezembro/2018, p. 52-90

www.revistas.usp.br/tradterm 


\section{Metodologia e Resultados}

Dada a complexidade do licenciamento ambiental, o primeiro passo para o desenvolvimento da pesquisa consistiu em melhor compreender este instrumento da Política Nacional de Meio Ambiente (PNMA) e sua organização, elaborando-se uma árvore de domínio (Fig. 01), forma de organização que tem por base as relações existentes entre os conceitos por ele abrangidos, pois, conforme Cabré (1999a: 99, tradução nossa ${ }^{5}$ ): «[...] termos não são unidades isoladas que ocorrem fora de um contexto [...] relacionam-se a todos os outros termos que constituem o mesmo domínio, com os quais eles formam um sistema conceitual».

Figura 1 - Árvore de domínio do licenciamento ambiental

\footnotetext{
${ }^{5}[\ldots .$.$] terms are not isolated units occurring outside a specific context, [...] terms are related$ to all the other terms that form part of the same special subject, with which they constitute a conceptual field.
} 


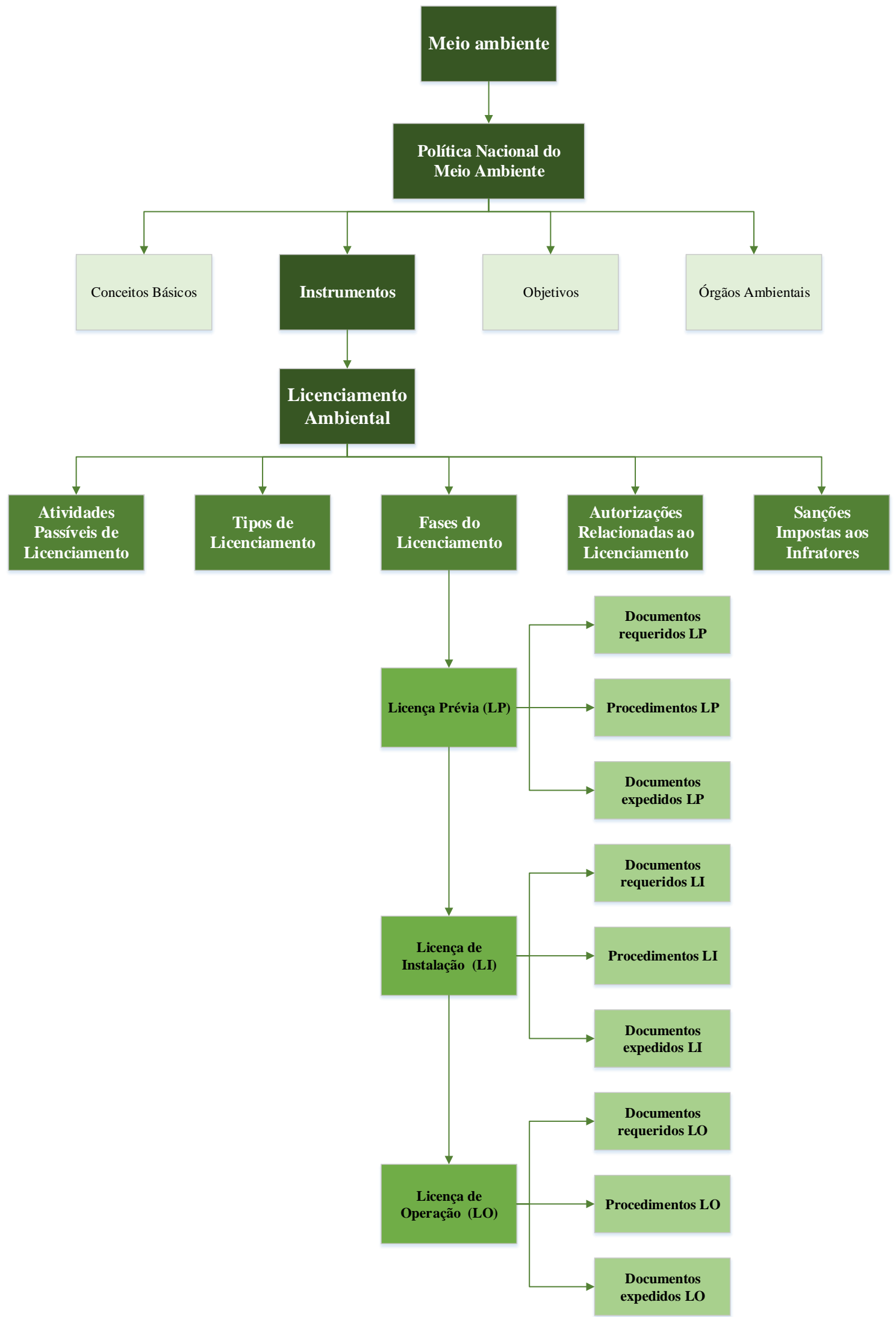

Fonte: Elaborado pela Autora

TradTerm, São Paulo, v. 32, dezembro/2018, p. 52-90

www.revistas.usp.br/tradterm 
Por indicar a posição de cada termo no sistema e as relações entre eles, o estabelecimento da árvore de domínio constitui etapa importante do trabalho terminológico e auxilia na realização de etapas posteriores, como a confirmação quanto ao pertencimento ou não de um candidato a termo a determinada área de especialidade.

Além da árvore de domínio, visando melhor compreender a área de estudo e a ter mais respaldo na escolha dos termos, construímos também fluxogramas do Licenciamento Ambiental. Fluxogramas são diagramas que representam esquematicamente os procedimentos envolvidos em uma atividade. Foram construídos quatro fluxogramas, sendo um para o licenciamento ordinário e outros três para o licenciamento com estudo de impacto ambiental, que se divide em três fases: prévia, como exemplifica a figura abaixo, de instalação e de operação. 
Figura 2 - Fluxograma do licenciamento ambiental com EIA/RIMA - Fase LP

Fluxograma do Licenciamento Ambiental Brasileiro

Empreendimentos de Significativo Impacto Ambiental, com exigência de EIA/RIMA

Fase 1; Licença Prévia - LP (autoriza o local do empreendimento)

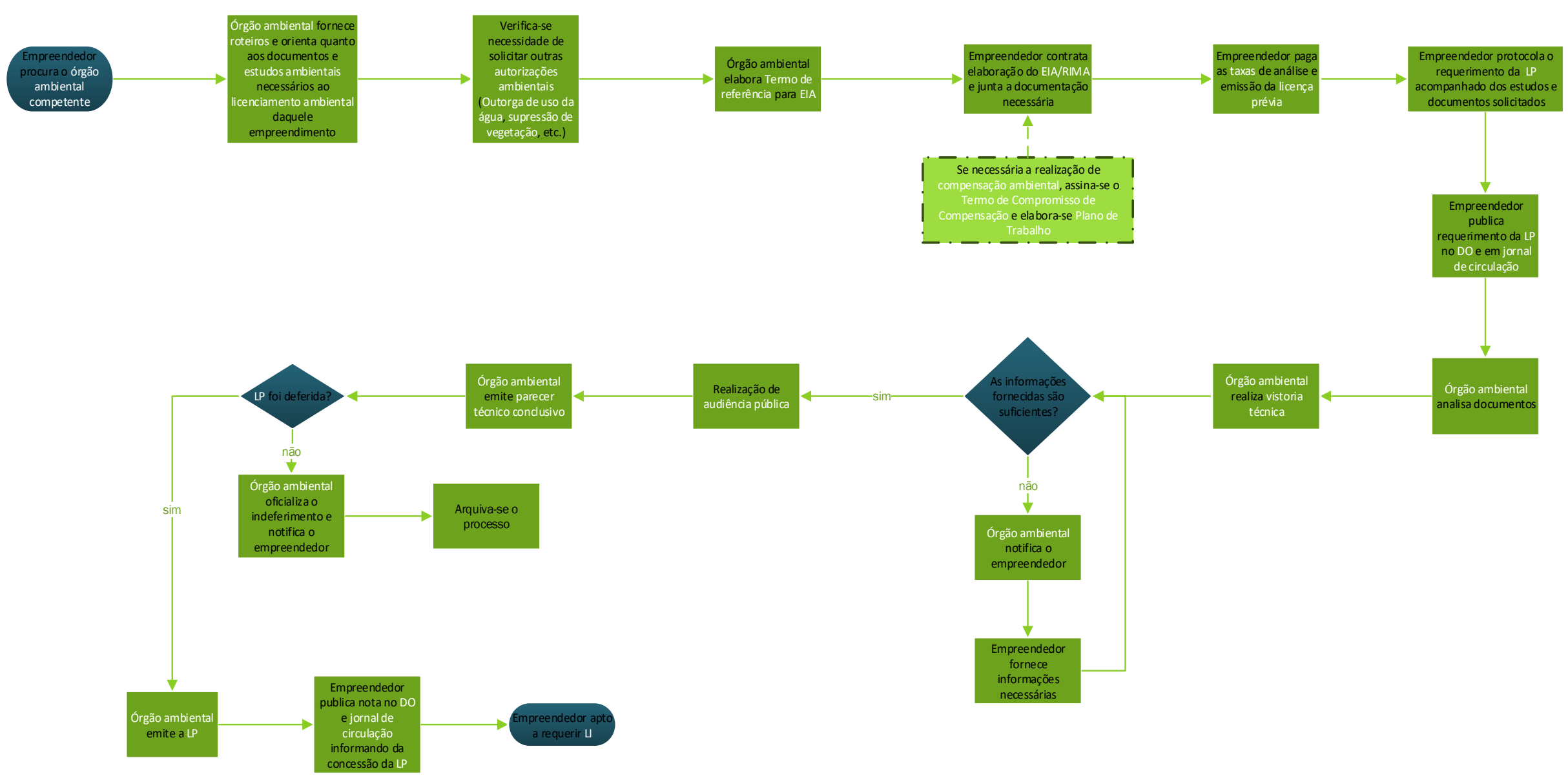

TradTerm, São Paulo, v. 32, dezembro/2018, p. 52-90

www.revistas.usp.br/tradterm 
A investigação dos termos do licenciamento ambiental em português se deu em um corpus especializado com o auxílio de um software utilizado em pesquisas linguísticas, caracterizando um trabalho de extração terminológica semiautomática.

As etapas metodológicas percorridas para a seleção e validação dos termos em português incluíram a organização e preparação do corpus; escolha do software para seu processamento e análise; seleção dos candidatos a termo; validação dos candidatos; eleição dos termos; e organização sistemática dos termos. Para a seleção dos equivalentes, partimos dos termos validados em português, percorrendo-se etapas semelhantes, tais como seleção e verificação dos candidatos; eleição dos equivalentes.

Ambos os corpora são compostos de 41 textos, divididos entre atos normativos relacionados ao licenciamento ambiental ( 38 em português, sendo 34 federais e 4 do estado de Mato Grosso; e 39 em inglês, todos federais) e manuais de licenciamento ( 3 em português - FIESP 2006; TCU 2007; SEBRAE 2012; 2 em inglês - California 2014; United States 2007). Os textos foram "limpos", de modo a excluir itens não textuais, como figuras e notas de rodapé, e convertidos em texto sem formatação (.txt), formato adequado ao processamento pela ferramenta informática escolhida.

O software escolhido para a análise do corpus foi o AntConc (ANTHONY 2014). Trata-se de um conjunto de sete ferramentas utilizado para a investigação linguística em corpus ou para o aprendizado com dados empíricos. Das sete ferramentas disponibilizadas pelo AntConc, utilizamos seis, sendo elas: word list, que conta e gera uma lista com as palavras do corpus e possibilita verificar rapidamente as palavras mais e menos frequentes; concordance, que permite averiguar como as palavras e frases são utilizadas no texto ao disponibilizar uma palavra-chave em contexto (KeyWord in Context - KWIC); concordance plot tool, que fornece dados de frequência e distribuição das palavras nos textos; cluster e n-gram, que permitem, respectivamente, explorar as combinações existentes, condicionando-as por palavra-chave que se deseje investigar, sua posição no agrupamento e o tamanho deste, ou observar todas as expressões comuns em um corpus de 
acordo com tamanho do agrupamento; e file view tool, que, ao mostrar cada arquivo de texto individualmente, permite a extrapolação dos contextos.

Assim, para as etapas de seleção e validação foram adotados os seguintes procedimentos: 1. Geração da lista de palavras com a aplicação de uma stoplist ${ }^{6} ; 2$. Verificação das palavras mais frequentes; 3. Verificação de colocados; 4. Averiguação de agrupamentos por n-gramas e de combinações com a ferramenta cluster; 5. Exame dos contextos das palavras e combinações; 6. Seleção dos candidatos a termo; 7. Cotejo dos candidatos com a árvore de domínio e os fluxogramas do licenciamento ambiental; 8. Consulta a analistas de meio ambiente sobre a lista de candidatos a termo; 9. Eleição dos termos; 10. Organização sistemática dos termos.

Para a seleção dos equivalentes, as etapas seguidas foram: 1. Geração da lista de palavras com a aplicação de uma stoplist; 2. Verificação das palavras mais frequentes; 3. Verificação de colocados; 4. Averiguação de agrupamentos por n-gramas e de combinações com a ferramenta cluster; 5. Exame dos contextos das palavras e combinações.

A seguir descrevemos os passos trilhados, exemplificando-os com os resultados obtidos.

\subsection{Resultados}

Após aplicarmos uma stoplist e solicitarmos uma wordlist ordenada pela frequência das palavras no corpus de pesquisa, que indicou as dez palavras mais frequentes do corpus:

Tabela 1 - Palavras mais frequentes do Corpus

\begin{tabular}{lll}
\hline Classificação & Frequência & \multicolumn{1}{c}{ Palavra } \\
\hline $\mathbf{1}$ & 1613 & ambiental \\
$\mathbf{2}$ & 1112 & art \\
$\mathbf{3}$ & 614 & licenciamento
\end{tabular}

\footnotetext{
${ }^{6}$ A stoplist é uma lista de palavras a ser ignorada pelo programa quando este processar os dados e foi utilizada para evitar "ruídos" ou palavras irrelevantes para pesquisa, tais como preposições, artigos e pronomes. Baseamo-nos numa lista obtida da internet (http://miningtext.blogspot.com.br/2008/11/listas-de-stopwords-stoplist-portugues.html), à qual acrescentamos algarismos romanos, comuns em textos legislativos, por exemplo.

TradTerm, São Paulo, v. 32, dezembro/2018, p. 52-90

www.revistas.usp.br/tradterm
} 


\begin{tabular}{lll}
4 & 574 & meio \\
$\mathbf{5}$ & 548 & órgão \\
6 & 532 & licença \\
7 & 496 & ambiente \\
8 & 446 & ambientais \\
9 & 395 & empreendimentos \\
10 & 390 & atividades \\
\hline
\end{tabular}

Fonte: elaborado pela Autora

A lista das palavras mais frequentes mostrou que o adjetivo ambiental se combinava com outras palavras constantes dessa lista formando termos sintagmáticos, a exemplo de licenciamento ambiental, licença ambiental e órgão ambiental. Por ser a palavra mais frequente e apresentar fortes indícios de ser um adjetivo produtivo para a formação de outros termos, utilizamos a ferramenta collocates para investigar seus colocados.

A busca foi configurada por palavras mais frequentes à esquerda, com uma janela de três palavras e frequência mínima de três ocorrências. A lista resultante confirmou a suposição a respeito da produtividade da palavra ambiental, pois retornou diversas palavras com alto valor de $\mathrm{Ml}^{7}$, ou seja, grande força de associação com a palavra-chave.

Tabela 2 - Colocados mais relevantes da palavra ambiental

\begin{tabular}{rccccl}
\hline Ordem & MI & $\begin{array}{c}\text { Total de } \\
\text { ocorrências }\end{array}$ & $\begin{array}{c}\text { Tot. Oc. à } \\
\text { esq. }\end{array}$ & $\begin{array}{c}\text { Tot. Oc. à } \\
\text { dir. }\end{array}$ & Palavra \\
\hline $\mathbf{1}$ & 5.08820 & 198 & 196 & 2 & impacto \\
$\mathbf{2}$ & 4.99818 & 68 & 68 & 0 & degradação \\
$\mathbf{3}$ & 4.90386 & 82 & 61 & 21 & relatório \\
$\mathbf{4}$ & 4.85771 & 78 & 71 & 7 & estudo \\
$\mathbf{5}$ & 4.72731 & 355 & 345 & 10 & órgão \\
$\mathbf{6}$ & 4.50942 & 342 & 335 & 7 & licenciamento \\
$\mathbf{7}$ & 3.81907 & 68 & 65 & 3 & controle \\
$\mathbf{8}$ & 3.07974 & 110 & 89 & 21 & licença \\
\hline
\end{tabular}

Fonte: elaborado pela Autora

A lista obtida traz alguns colocados com os quais o adjetivo ambiental se combina para formar termos sintagmáticos, tais como impacto ambiental

\footnotetext{
${ }^{7} \mathrm{Ml}$ refere-se a Mutual Information, um coeficiente de força de associação entre as palavras (EVERT 2005). Quanto mais alto o valor de MI, maior a força de associação de entre as palavras. Nessa pesquisa, consideramos valores de MI acima de 2.
} 
$(M I=5,08)$ e degradação ambiental $(M I=4,99)$ e estudo ambiental $(M I=$ $4,85)$. Estendendo a análise dos colocados e de suas concordâncias para as dez primeiras palavras da lista de frequência, destacaram-se os altos valores de MI para alguns colocados, a exemplo de licença + prévia $(M I=6,57)$, licenciamento + simplificado $(M I=6,12)$, licença + instalação $(M I=6,05)$ e licença + operação $(M l=5,65)$. Verificamos, além dos candidatos a termo formados imediatamente pela palavra-chave e seu colocado, como os relatados, diversos outros candidatos formados pela combinação com outras palavras, por expansão do sintagma, como em licenciamento ambiental corretivo, licenciamento ambiental simplificado, estudo de impacto ambiental, avaliação de impacto ambiental, relatório de impacto ambiental, meio ambiente ecologicamente equilibrado, licença prévia para perfuração, entre outros.

O próximo passo consistiu em aprofundar a busca por termos sintagmáticos, o que se deu por meio das ferramentas n-grams e clusters. Buscando melhor visualização dos resultados gerados, configuramos a ferramenta $n$-grams para que a lista fosse ordenada por frequência e limitamos os tamanhos dos agrupamentos em duas, três, quatro e cinco palavras, obtendo quatro listas diferentes, uma para cada tamanho. A averiguação dos cem agrupamentos mais frequentes de cada lista retornou combinações relevantes para a temática em estudo, como se pode ver no quadro 1 a seguir.

Quadro 1 - Agrupamentos relevantes obtidos com a ferramenta N-gram

\begin{tabular}{|c|c|c|c|}
\hline \multicolumn{4}{|c|}{ Tamanho do N-grama } \\
\hline Duas palavras & Três palavras & Quatro palavras & Cinco palavras \\
\hline $\begin{array}{l}\text { impacto } \\
\text { ambiental }\end{array}$ & $\begin{array}{c}\text { área de } \\
\text { influência }\end{array}$ & $\begin{array}{c}\text { áreas de } \\
\text { preservação } \\
\text { permanente }\end{array}$ & $\begin{array}{c}\text { conselho } \\
\text { nacional do } \\
\text { meio ambiente }\end{array}$ \\
\hline $\begin{array}{c}\text { licença } \\
\text { ambiental }\end{array}$ & auto de infração & $\begin{array}{c}\text { áreas de proteção } \\
\text { ambiental }\end{array}$ & $\begin{array}{c}\text { instituto } \\
\text { brasileiro do } \\
\text { meio ambiente }\end{array}$ \\
\hline $\begin{array}{c}\text { recursos } \\
\text { ambientais }\end{array}$ & $\begin{array}{l}\text { órgão ambiental } \\
\text { licenciador }\end{array}$ & $\begin{array}{l}\text { estudo de } \\
\text { impacto } \\
\text { ambiental }\end{array}$ & $\begin{array}{l}\text { pequeno } \\
\text { potencial de } \\
\text { impacto } \\
\text { ambiental }\end{array}$ \\
\hline licença prévia & $\begin{array}{l}\text { relatório de } \\
\text { impacto }\end{array}$ & $\begin{array}{c}\text { medidas } \\
\text { mitigadoras e }\end{array}$ & $\begin{array}{c}\text { política } \\
\text { nacional do }\end{array}$ \\
\hline
\end{tabular}

TradTerm, São Paulo, v. 32, dezembro/2018, p. 52-90

www.revistas.usp.br/tradterm 


\begin{tabular}{|c|c|c|c|}
\hline $\begin{array}{c}\text { licenciamento } \\
\text { ambiental }\end{array}$ & $\begin{array}{c}\text { termo de } \\
\text { compromisso }\end{array}$ & $\begin{array}{c}\text { compensatórias } \\
\text { potencial de } \\
\text { impacto } \\
\text { ambiental }\end{array}$ & meio ambiente \\
\hline meio ambiente & $\begin{array}{c}\text { estudo de } \\
\text { impacto }\end{array}$ & $\begin{array}{c}\text { relatório de } \\
\text { impacto } \\
\text { ambiental }\end{array}$ & $\ldots$ \\
\hline $\begin{array}{c}\text { resolução } \\
\text { Conama }\end{array}$ & $\begin{array}{c}\text { órgão ambiental } \\
\text { competente }\end{array}$ & $\ldots$ & $\ldots$ \\
\hline
\end{tabular}

Fonte: elaborado pela Autora

Além de revelar candidatos a termo, a busca por n-gramas possibilitou apurar a recorrência de padrões de combinação dos termos sintagmáticos, tais como $\mathrm{N}+$ Adj (recursos ambientais), N1 + prep. + N2 + Adj (área de preservação permanente), $\mathrm{N}$ + Adj1 + Adj2 (órgão ambiental competente) e N1 + prep. + N2 (licença de operação). Ao examinar a concordância desses candidatos, foi possível identificar, ainda, sintagmas com mais de cinco palavras, como em Instituto Brasileiro do Meio Ambiente que se estende para Instituto Brasileiro do Meio Ambiente e dos Recursos Naturais Renováveis.

Visando uma busca mais refinada, foram investigados clusters de tamanho entre duas e cinco palavras para as cem palavras mais frequentes no corpus. Tomando por referência a palavra ambiental, buscamos, inicialmente, clusters de duas palavras, com o adjetivo ambiental alinhado à direita. Assim, obtivemos uma lista de 125 combinações, das quais a tabela 3 destaca as 20 mais frequentes:

Tabela 3 - Clusters de tamanho dois com a palavra-chave ambiental

\begin{tabular}{rccl}
\hline Ordem & Frequência & Distribuição & \multicolumn{1}{c}{ Cluster } \\
\hline 1 & 309 & 37 & licenciamento ambiental \\
2 & 222 & 30 & órgão ambiental \\
3 & 187 & 25 & impacto ambiental \\
4 & 79 & 22 & licença ambiental \\
5 & 50 & 13 & degradação ambiental \\
6 & 46 & 13 & qualidade ambiental \\
7 & 43 & 15 & controle ambiental \\
8 & 40 & 14 & proteção ambiental
\end{tabular}

TradTerm, São Paulo, v. 32, dezembro/2018, p. 52-90

www.revistas.usp.br/tradterm 


\begin{tabular}{cccl}
9 & 35 & 4 & autoridade ambiental \\
10 & 25 & 10 & relatório ambiental \\
11 & 23 & 5 & compensação ambiental \\
12 & 21 & 9 & gestão ambiental \\
13 & 21 & 13 & legislação ambiental \\
14 & 20 & 5 & infração ambiental \\
15 & 18 & 13 & diagnóstico ambiental \\
16 & 16 & 7 & educação ambiental \\
17 & 15 & 3 & dano ambiental \\
18 & 15 & 8 & viabilidade ambiental \\
19 & 14 & 9 & interesse ambiental \\
20 & 11 & 4 & fiscalização ambiental \\
\hline
\end{tabular}

Fonte: Elaborado pela Autora

Aparentemente, todas essas combinações poderiam ser candidatas a termo da área estudada. Por esta razão, os clusters retornados nesta amostra foram então verificados por meio das ferramentas Concordance (que permite a visualização do contexto de cada palavra).

Essa fase da pesquisa oportunizou constatar a existência de variação. Tal fenômeno pôde ser percebido de diversas formas: por meio das siglas e acrônimos (estudo de impacto ambiental - ElA, relatório de impacto ambiental - RIMA, Instituto Brasileiro do Meio Ambiente e dos Recursos Naturais Renováveis - IBAMA, etc.); de alterações morfossintáticas (curso d'água - curso de água); de alterações lexicais (qualidade do meio ambiente qualidade ambiental, medidas mitigatórias - medidas mitigadoras, área de sensibilidade ambiental - área ambientalmente sensivel); de reduções (impacto ambiental local - impacto local); e de variantes denominativas (termo de ajustamento de conduta - termo de compromisso ambiental, autorização de desmatamento - autorização de supressão de vegetação).

Durante as etapas de identificação e recolha, procuramos selecionar os candidatos considerando sua frequência e distribuição no corpus $^{8}$, além da

8 O número de corte para os critérios de frequência e distribuição, considerando-se o tamanho do corpus, foi de duas (2) ocorrências.

TradTerm, São Paulo, v. 32, dezembro/2018, p. 52-90

www.revistas.usp.br/tradterm 
pertinência ao tema. Assim, foram selecionados candidatos como estudos ambientais, com 53 ocorrências distribuídas em 14 textos, ou licença de operação, com 78 ocorrências distribuídas em 18 textos, pois se mostraram altamente pertinentes ao tema, segundo seus contextos. No entanto, foram encontrados sintagmas de frequência igual a um, como termo de compromisso ambiental, ou de distribuição igual a um, como risco ambiental, considerados relevantes para a pesquisa apesar da frequência e/ou distribuição abaixo do número de corte estipulado.

A importância destes candidatos para a área de especialidade foi determinada com base na avaliação de seus contextos, pelos quais apuramos que um termo de compromisso ambiental seria um documento firmado pelo órgão fundiário e pelo assentado responsável ${ }^{9}$ pela atividade agrossilvipastoril ou empreendimento de infraestrutura, mediante o qual se comprometem a promover a regularização ambiental, dentro do prazo e condições a serem especificados pelo órgão ambiental competente (Resolução Conama 458/2013). Do mesmo modo, relatório de impacto ambiental de sísmica - RIAS é o documento elaborado pelo empreendedor que apresenta a síntese do EAS em linguagem acessível aos interessados, demonstrando as consequências ambientais da implementação das atividades de aquisição de dados sísmicos (Resolução Conama 350/2004).

A validação dos candidatos a termo elencados se deu a partir do cotejo desses candidatos com a árvore de domínio e com os fluxogramas do licenciamento ambiental, visando estabelecer relações entre eles, encaixando os candidatos nestes diagramas, conforme exemplificado no quadro 2 .

Quadro 2 - Correlações dos candidatos a termo com a árvore de domínio e fluxogramas do licenciamento ambiental

\begin{tabular}{|c|c|c|c|c|}
\hline $\begin{array}{c}\text { Candidato a } \\
\text { termo }\end{array}$ & $\begin{array}{c}\text { Correlação com } \\
\text { a árvore de } \\
\text { domínio }\end{array}$ & $\begin{array}{c}\text { Correlação } \\
\text { com } \\
\text { fluxograma } \\
\text { s }\end{array}$ & $\begin{array}{c}\text { Configura } \\
\text { termo da } \\
\text { área? }\end{array}$ & Justificativa \\
\hline Áreas de & Espaço territorial & Não aparece & Sim & Podem \\
\hline
\end{tabular}

9 Assentado responsável se refere a agricultores ou trabalhadores instalados em assentamentos rurais como resultado de políticas públicas, objetivando uma redistribuição de terras menos concentradora, cujos envolvidos são os trabalhadores rurais sem-terra e aqueles com pouca terra. Trata-se do assentado que possui a posse da terra.

TradTerm, São Paulo, v. 32, dezembro/2018, p. 52-90

www.revistas.usp.br/tradterm 


\begin{tabular}{|c|c|c|c|c|}
\hline $\begin{array}{l}\text { proteção } \\
\text { ambiental - } \\
\text { APAS }\end{array}$ & $\begin{array}{l}\text { legalmente } \\
\text { protegido - tipo } \\
\text { de }\end{array}$ & $\begin{array}{l}\text { no } \\
\text { fluxograma }\end{array}$ & & $\begin{array}{l}\text { interferir no } \\
\text { licenciamento }\end{array}$ \\
\hline $\begin{array}{l}\text { Compensaçã } \\
\text { o ambiental }\end{array}$ & $\begin{array}{l}\text { Penalidades } \\
\text { compensatórias / } \\
\text { sanções impostas } \\
\text { aos infratores - } \\
\text { tipo de }\end{array}$ & $\begin{array}{l}\text { Procedimen } \\
\text { to exigido } \\
\text { quando se } \\
\text { constatam } \\
\text { danos } \\
\text { ambientais } \\
\text { ou impactos } \\
\text { não } \\
\text { mitigáveis }\end{array}$ & Sim & $\begin{array}{l}\text { Procedimento } \\
\text { integrante das } \\
\text { etapas de } \\
\text { licenciamento }\end{array}$ \\
\hline $\begin{array}{l}\text { Controle } \\
\text { ambiental }\end{array}$ & $\begin{array}{l}\text { Procedimentos } \\
\text { do licenciamento } \\
\text { ambiental / fase } \\
\text { LI }\end{array}$ & $\begin{array}{l}\text { Não aparece } \\
\text { no } \\
\text { fluxograma }\end{array}$ & Sim & $\begin{array}{l}\text { Procedimento } \\
\text { integrante das } \\
\text { etapas de } \\
\text { licenciamento }\end{array}$ \\
\hline $\begin{array}{l}\text { Degradação } \\
\text { ambiental }\end{array}$ & $\begin{array}{l}\text { Pode ser } \\
\text { consequência de } \\
\text { uma atividade ou } \\
\text { empreendimento }\end{array}$ & $\begin{array}{l}\text { Não aparece } \\
\text { no } \\
\text { fluxograma }\end{array}$ & Sim & $\begin{array}{l}\text { Pode estar } \\
\text { relacionada à } \\
\text { atividade em } \\
\text { licenciamento }\end{array}$ \\
\hline $\begin{array}{l}\text { Diagnóstico } \\
\text { ambiental }\end{array}$ & $\begin{array}{l}\text { Documentos } \\
\text { requeridos / fase } \\
\text { LP }\end{array}$ & $\begin{array}{l}\text { Não aparece } \\
\text { no } \\
\text { fluxograma }\end{array}$ & Sim & $\begin{array}{l}\text { Documento } \\
\text { exigido no } \\
\text { processo de } \\
\text { licenciamento }\end{array}$ \\
\hline $\begin{array}{l}\text { Educação } \\
\text { ambiental }\end{array}$ & $\begin{array}{l}\text { Objetivo da } \\
\text { PNMA }\end{array}$ & $\begin{array}{l}\text { Não aparece } \\
\text { no } \\
\text { fluxograma }\end{array}$ & Não & Ligada à PNMA \\
\hline $\begin{array}{l}\text { Gestão } \\
\text { ambiental }\end{array}$ & $\begin{array}{l}\text { Objetivo da } \\
\text { PNMA }\end{array}$ & $\begin{array}{l}\text { Não aparece } \\
\text { no } \\
\text { fluxograma }\end{array}$ & Não & $\begin{array}{l}\text { Envolve o } \\
\text { licenciamento } \\
\text { ambiental }\end{array}$ \\
\hline $\begin{array}{l}\text { Impacto } \\
\text { ambiental } \\
\text { significativo }\end{array}$ & $\begin{array}{l}\text { Pode ser } \\
\text { consequência de } \\
\text { uma atividade ou } \\
\text { empreendimento }\end{array}$ & $\begin{array}{l}\text { Não aparece } \\
\text { no } \\
\text { fluxograma }\end{array}$ & Sim & $\begin{array}{l}\text { Pode ser } \\
\text { causado pela } \\
\text { atividade em } \\
\text { licenciamento }\end{array}$ \\
\hline $\begin{array}{l}\text { Infração } \\
\text { ambiental }\end{array}$ & $\begin{array}{l}\text { Sanções impostas } \\
\text { aos infratores - } \\
\text { causa de }\end{array}$ & $\begin{array}{l}\text { Não aparece } \\
\text { no } \\
\text { fluxograma }\end{array}$ & Sim & $\begin{array}{l}\text { Pode ser } \\
\text { cometida pelo } \\
\text { responsável } \\
\text { pela atividade } \\
\text { em } \\
\text { licenciamento }\end{array}$ \\
\hline $\begin{array}{l}\text { Licença } \\
\text { ambiental }\end{array}$ & $\begin{array}{l}\text { Documentos } \\
\text { emitidos - todas } \\
\text { as fases, } \\
\text { dependendo do } \\
\text { tipo de }\end{array}$ & $\begin{array}{l}\text { Documento } \\
\text { solicitado / } \\
\text { expedido }\end{array}$ & Sim & $\begin{array}{l}\text { Documento } \\
\text { emitido ao final } \\
\text { do processo de } \\
\text { licenciamento }\end{array}$ \\
\hline $\begin{array}{l}\text { Licenciamen } \\
\text { to ambiental } \\
\text { simplificado }\end{array}$ & $\begin{array}{l}\text { Instrumento da } \\
\text { PNMA - tipo de }\end{array}$ & $\begin{array}{l}\text { Não aparece } \\
\text { no } \\
\text { fluxograma }\end{array}$ & Sim & $\begin{array}{l}\text { Procedimento } \\
\text { administrativo } \\
\text { diferenciado } \\
\text { para atividades }\end{array}$ \\
\hline
\end{tabular}




\begin{tabular}{|c|c|c|c|c|}
\hline & & & & $\begin{array}{l}\text { de baixo } \\
\text { impacto }\end{array}$ \\
\hline $\begin{array}{l}\text { Órgão } \\
\text { ambiental }\end{array}$ & $\begin{array}{l}\text { Órgãos } \\
\text { executores da } \\
\text { PNMA }\end{array}$ & $\begin{array}{l}\text { Não aparece } \\
\text { no } \\
\text { fluxograma }\end{array}$ & Sim & $\begin{array}{l}\text { Executores da } \\
\text { PNMA e do } \\
\text { licenciamento }\end{array}$ \\
\hline $\begin{array}{l}\text { Plano de } \\
\text { compensaçã } \\
\text { o ambiental }\end{array}$ & $\begin{array}{l}\text { Documentos } \\
\text { requeridos / fase } \\
\text { LP - tipo de }\end{array}$ & $\begin{array}{l}\text { Não aparece } \\
\text { no } \\
\text { fluxograma }\end{array}$ & Sim & $\begin{array}{l}\text { Documento } \\
\text { exigido no } \\
\text { processo de } \\
\text { licenciamento }\end{array}$ \\
\hline $\begin{array}{l}\text { Proteção } \\
\text { ambiental }\end{array}$ & $\begin{array}{l}\text { Ligada aos } \\
\text { objetivos da } \\
\text { PNMA }\end{array}$ & $\begin{array}{l}\text { Não aparece } \\
\text { no } \\
\text { fluxograma }\end{array}$ & Sim & $\begin{array}{l}\text { Conjunto de } \\
\text { medidas que } \\
\text { são tomadas } \\
\text { para cuidar do } \\
\text { meio ambiente, } \\
\text { preservá-lo da } \\
\text { contaminação e } \\
\text { deterioração }\end{array}$ \\
\hline $\begin{array}{l}\text { Qualidade } \\
\text { ambiental }\end{array}$ & $\begin{array}{l}\text { Conceitos básicos } \\
\text { da PNMA }\end{array}$ & $\begin{array}{l}\text { Não aparece } \\
\text { no } \\
\text { fluxograma }\end{array}$ & Sim & $\begin{array}{l}\text { Objetivo da } \\
\text { PNMA }\end{array}$ \\
\hline $\begin{array}{l}\text { Relatório de } \\
\text { qualidade } \\
\text { ambiental }\end{array}$ & $\begin{array}{l}\text { Documentos } \\
\text { requeridos / fase } \\
\text { LI - tipo de }\end{array}$ & $\begin{array}{l}\text { Não aparece } \\
\text { no } \\
\text { fluxograma }\end{array}$ & Sim & $\begin{array}{l}\text { Documento } \\
\text { exigido no } \\
\text { processo de } \\
\text { licenciamento }\end{array}$ \\
\hline $\begin{array}{l}\text { Relatório de } \\
\text { qualidade do } \\
\text { meio } \\
\text { ambiente }\end{array}$ & $\begin{array}{l}\text { Documentos } \\
\text { requeridos / fase } \\
\text { LI - tipo de }\end{array}$ & $\begin{array}{l}\text { Não aparece } \\
\text { no } \\
\text { fluxograma }\end{array}$ & Sim & $\begin{array}{l}\text { Documento } \\
\text { exigido no } \\
\text { processo de } \\
\text { licenciamento }\end{array}$ \\
\hline $\begin{array}{l}\text { Servidão } \\
\text { ambiental }\end{array}$ & $\begin{array}{l}\text { Instrumento } \\
\text { econômico da } \\
\text { PNMA - tipo de }\end{array}$ & $\begin{array}{l}\text { Não aparece } \\
\text { no } \\
\text { fluxograma }\end{array}$ & $\begin{array}{l}\text { Sim, } \\
\text { indiretame } \\
\text { nte }\end{array}$ & $\begin{array}{l}\text { Mecanismo } \\
\text { legal de } \\
\text { autolimitação } \\
\text { de uso de terras } \\
\text { por parte dos } \\
\text { proprietários } \\
\text { para a } \\
\text { preservação } \\
\text { ambiental }\end{array}$ \\
\hline
\end{tabular}

Fonte: elaborado pela Autora

A etapa de validação, aliada às informações de frequência, distribuição e uso em contexto, serviu para definir quais dos candidatos configurariam termos do licenciamento ambiental. A lista de termos foi, ainda, submetida à avaliação de dois especialistas da área, também analistas de meio ambiente da SEMA-MT, sendo um do Direito ambiental e outro da Engenharia florestal. Além de corroborarem os termos já validados na pesquisa, os especialistas 
sugeriram termos que não haviam sido coletados, tais como floresta nacional e interdição. Antes de sua inserção na lista, os termos sugeridos foram investigados no corpus, com vistas a verificar sua presença, frequência, distribuição e contexto. Constatamos que floresta nacional (encontrado no corpus em sua forma plural com frequência 2 e distribuição 2 ) é um tipo de unidade de conservação e, portanto, um espaço territorial legalmente protegido (Lei n. 9.605/1998). Já o termo interdição (frequência 7 e distribuição 4) relaciona-se às sanções impostas contra os infratores, pois trata-se de uma pena aplicada quando o estabelecimento, obra ou atividade estiver funcionando sem a devida autorização, ou em desacordo com a autorização concedida, ou com violação de disposição legal ou regulamentar (Lei n. 9.605/1998).

Depois de validados, os termos foram organizados sistematicamente em forma de mapa conceitual, elaborado com base nas relações estabelecidas com a árvore de domínio e os fluxogramas. Um mapa conceitual consiste num "conjunto estruturado de conceitos construído com base nas relações estabelecidas entre esses conceitos e no qual cada conceito é determinado por sua posição nesse conjunto" (ISO 1087, 1990, p. 4) ou, simplesmente, num recurso gráfico para a organização e representação de uma área de conhecimento, construído a partir das relações entre os conceitos que a compõe.

Utilizou-se o programa CMap Tools $^{10}$ para a construção do mapa conceitual. Contudo, resultaram desse processo 19 mapas conceituais, o que dificultava a compreensão do domínio estudado via ilustração. Em decorrência disso, optamos por utilizar outro recurso gráfico para a organização sistemática dos termos. 0 recurso escolhido foi o grafo, construído a partir da ferramenta Gephi11. Ambos os modelos de organização, mapa conceitual e grafo, podem ser vistos nas figuras 3,4 e 5 abaixo.

\footnotetext{
${ }^{10}$ Disponível gratuitamente em http://cmap.ihmc.us/.

${ }^{11}$ Disponível gratuitamente em: https://gephi.org/.

TradTerm, São Paulo, v. 32, dezembro/2018, p. 52-90

www.revistas.usp.br/tradterm
} 
Figura 3 - Mapa conceitual dos estudos ambientais

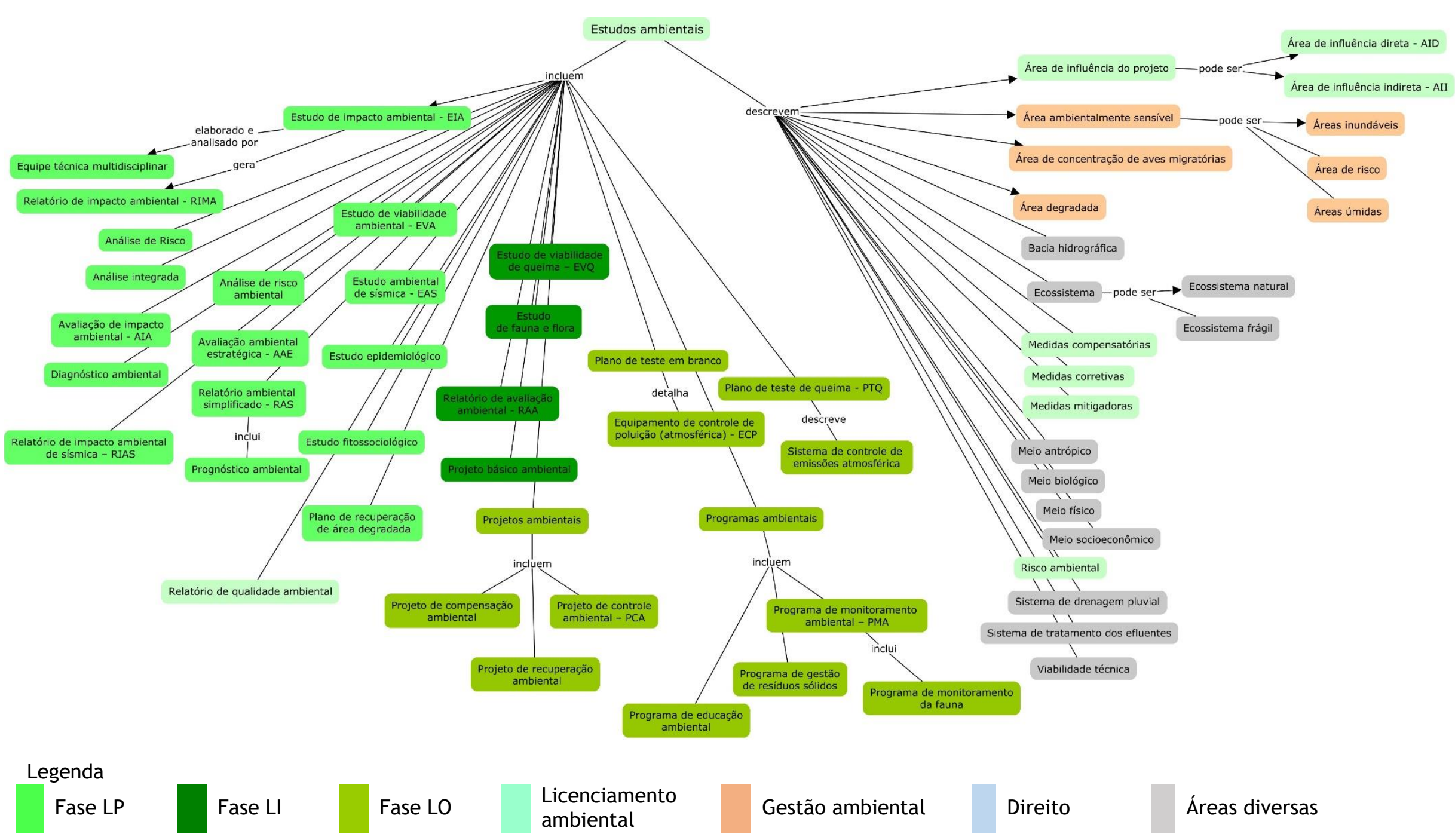

TradTerm, São Paulo, v. 32, dezembro/2018, p. 52-90

www.revistas.usp.br/tradterm 
Figura 4 - Visão geral do grafo "Termos do licenciamento ambiental”

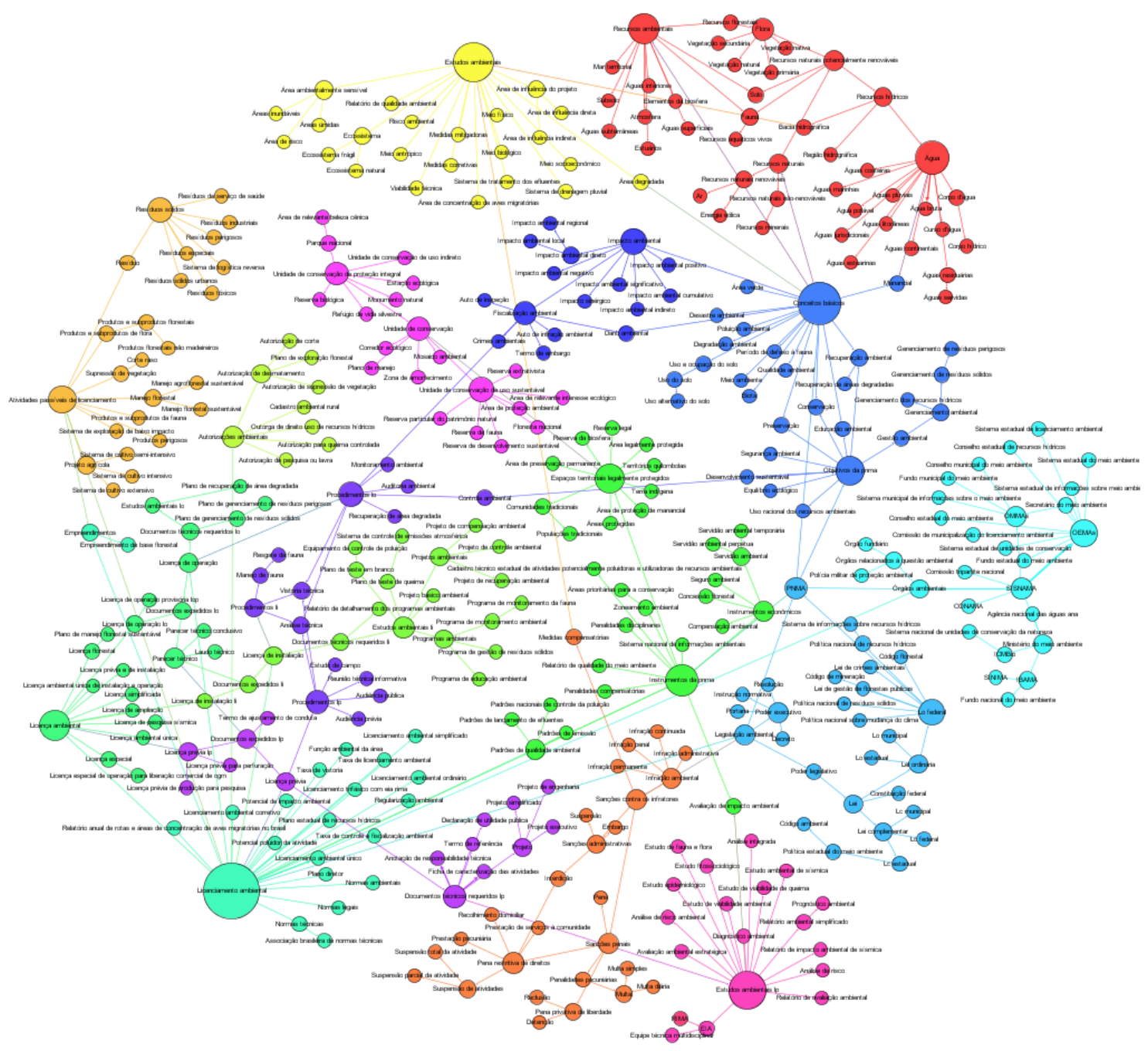

Fonte: elaborado pela autora 
Figura 5 - Recorte ampliado do grafo "Termos do licenciamento ambiental"

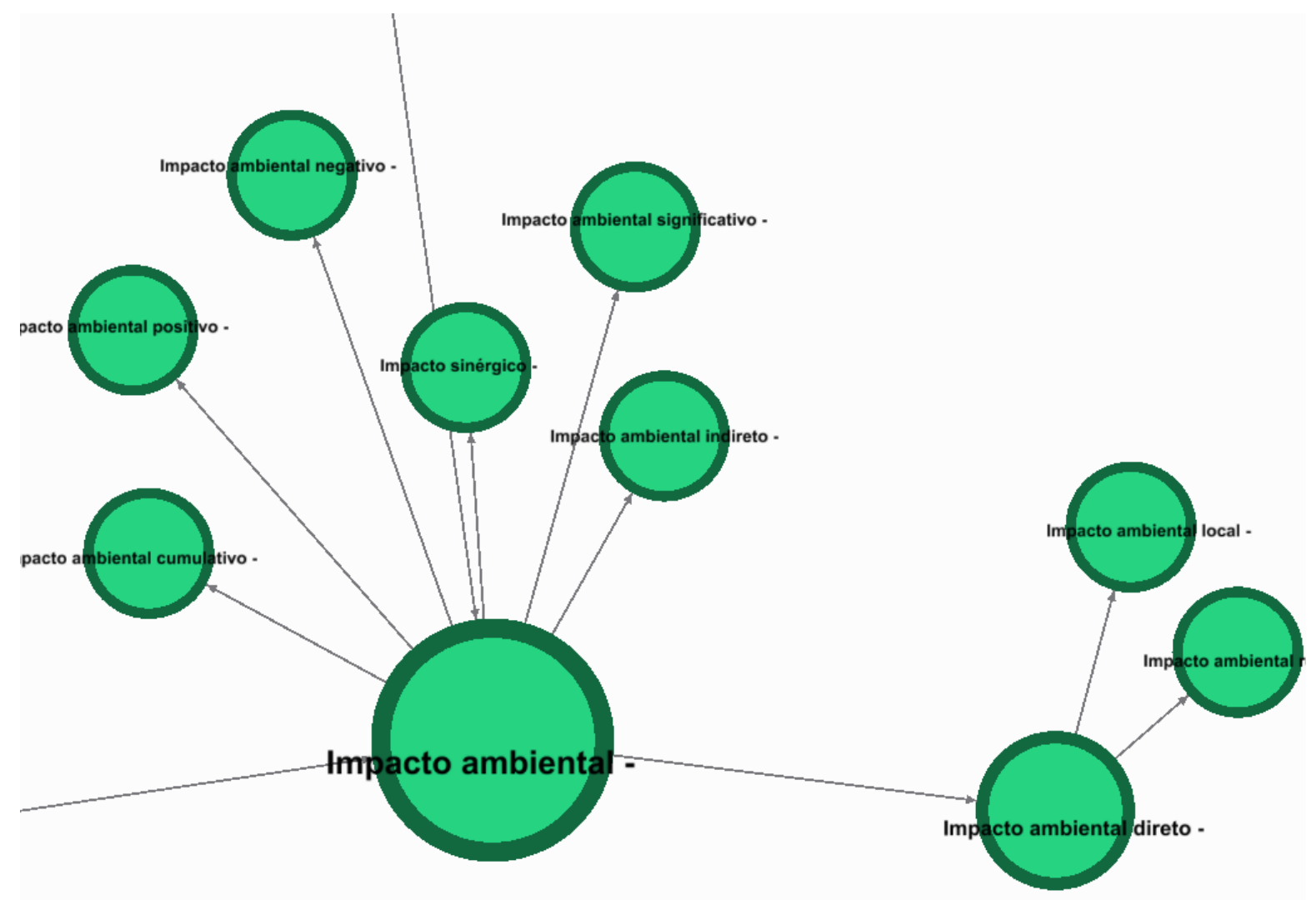

Fonte: elaborado pela autora

Com os termos definidos, partimos em busca dos equivalentes em inglês, seguindo os passos relatados na metodologia.

Quanto às palavras mais frequentes, observamos que as dez primeiras palavras não se assemelhavam àquelas da lista em português.

Tabela 4 - Dez palavras mais frequentes do corpus em inglês comparadas às do português

\begin{tabular}{lllll}
\hline Ordem & Freq. & Palavras (EnAm) & Freq. & Palavras (PtBr) \\
\hline $\mathbf{1}$ & 19885 & section & 1613 & ambiental \\
$\mathbf{2}$ & 11701 & title & 1112 & art \\
$\mathbf{3}$ & 8762 & administrator & 614 & licenciamento \\
$\mathbf{4}$ & 7686 & secretary & 574 & meio \\
$\mathbf{5}$ & 7621 & state & 548 & órgão \\
\hline
\end{tabular}




\begin{tabular}{lllll}
\hline 6 & 6136 & subsection & 532 & licença \\
7 & 5811 & act & 496 & ambiente \\
8 & 5040 & agency & 446 & ambientais \\
9 & 4963 & federal & 395 & empreendimento \\
10 & 4919 & states & 390 & atividades \\
\hline
\end{tabular}

Fonte: elaborado pela autora

Como tais palavras pouco auxiliavam nossa busca por equivalentes, ampliamos a visualização para as cem palavras mais frequentes, dentre as quais, tomando por referência os termos coletados em português, destacamos environmental (ambiental) na $17^{\mathrm{a}}$ posição, project (projeto) na $24^{\mathrm{a}}$, management (gestão, gerenciamento ou manejo) na $27^{\mathrm{a}}$, report (relatório) na $47^{\mathrm{a}}$, e permit (autorização) na $50^{\mathrm{a}}$.

0 passo seguinte foi verificar os $n$-gramas. Novamente geramos $n$ gramas de tamanhos entre duas e cinco palavras, os quais retornaram combinações relevantes, tais como environmental protection (freq. 707, dist. 30); national forest (freq. 705, dist. 7); environmental impact (freq. 685, dist. 24); operating license (freq. 74, dist. 4); environmental protection agency (freq. 652, dist. 27); e national environmental policy (freq. 181, dist. 23).

Como em português detectamos alta produtividade para o adjetivo ambiental, iniciamos a busca por clusters em inglês com o seu equivalente, environmental, requisitando a busca com o adjetivo à esquerda, visto que em inglês os adjetivos antecedem os substantivos. Observamos que o adjetivo environmental ocorreu 3.453 vezes nos 41 textos do corpus, resultado que indicava que poderia produzir combinações relevantes para a investigação. Os resultados foram promissores, com a indicação de diversos candidatos a equivalentes.

A partir da investigação de clusters com o adjetivo environmental, observamos que os padrões de combinação mais frequentes em inglês, $\operatorname{Adj}+\mathrm{N}$ e Adj + N1 + N2, diferem daqueles encontrados em português. Os padrões de combinação distintos refletem as diferenças sintáticas existentes entre as línguas, especialmente no que diz respeito à posição dos adjetivos, pois, em 
português, adjetivos normalmente sucedem o substantivo $(\mathrm{N}+\mathrm{Adj})$, enquanto em inglês costumam antecedê-lo.

Posteriormente, investigações mais aprofundadas como a de permit e license foram necessárias na busca por outros equivalentes, como no caso do termo impacto ambiental e seus derivados. Observamos que tanto impact quanto effect eram utilizados para se referir ao conceito de impacto. Decorridas as pesquisas no corpus e fora dele, compreendemos que impact e effect possuem significados semelhantes, embora effect esteja mais relacionado ao "resultado de" e impact à "influência de". Observamos que, apesar de não serem exatamente a mesma coisa, no domínio ambiental são intercambiáveis ${ }^{12}$, de modo que podemos ter environmental impact/effect, cumulative impact/effect, direct environmental impact/effect, significant environmental impact/effect, entre outros.

Destacamos, também, o caso do equivalente para o termo relatório de impacto ambiental. A princípio, o equivalente parecia ser environmental impact statement - EIS, relatório detalhado que descreve os impactos de um empreendimento ou atividade sobre o meio ambiente, bem como as medidas mitigadoras e alternativas à atividade em questão, subsidiando a tomada de decisão do órgão ambiental sobre a concessão ou não da licença. No entanto, também encontramos, para tal conceito, o termo environmental impact report - EIR e foi preciso aprofundar a pesquisa para avaliar os candidatos e selecionar o melhor equivalente.

No corpus, encontramos informações que nos levaram a considerar que os dois documentos seriam iguais, pois environmental impact report foi descrito como um relatório informativo, preparado a pedido do órgão ambiental com o propósito de fornecer informações detalhadas sobre os impactos de determinado projeto ou atividade no meio ambiente, além de relacionar medidas de mitigação dos possíveis impactos e indicar alternativas ao projeto proposto (USO4OCACEQAG, SC. $\left.15362^{13}\right)^{14}$. Também identificamos

\footnotetext{
${ }^{12}$ For purposes of NEPA, "effects" and "impacts" mean the same thing (UNITED STATES 2007: 17)

${ }^{13}$ US040CACEQAG, Sc. 15362, nomenclatura criada para organizar os textos do corpus em inglês, nesse caso se refere ao documento California Environmental Quality Act: Statute and Guidelines, seção 15362

${ }^{14} \mathrm{An}$ environmental impact report is an informational document which, when its preparation is required by this division, shall be considered by every public agency prior to its approval or TradTerm, São Paulo, v. 32, dezembro/2018, p. 52-90 
que ambos eram solicitados apenas quando uma atividade ou um empreendimento fossem classificados como "de significativo impacto ambiental".

O próprio corpus revelou que a diferença entre os termos se daria em relação à esfera de poder à qual pertence o órgão licenciador que solicita o relatório, de modo que apenas a Agência de Proteção Ambiental nacional americana solicitaria um EIS (US040CACEQAG, Sc. 15363) ${ }^{15}$. Além de tal característica estar explícita no texto, a mesma é corroborada pelo fato de as 402 ocorrências do termo environmental impact report se darem apenas no texto proveniente da esfera estatal, o California Environmental Quality Act: Statute and Guidelines. No licenciamento ambiental brasileiro, um RIMA pode ser solicitado tanto por um órgão licenciador federal quanto estadual, não se caracterizando, por essa razão, como um documento diferente. Dessa forma, optamos por manter os dois termos como equivalentes de relatório de impacto ambiental, acrescentando uma nota explicativa sobre o uso em inglês.

Assim, ao longo das investigações, pudemos separar os equivalentes encontrados entre equivalentes funcionais e equivalentes parciais.

Os casos em que o equivalente cobria apenas parcialmente o conceito em português foram identificados como equivalentes parciais. Nessas situações, utilizamos o recurso de expansão lexical para aproximar os significados dos equivalentes aos dos termos. Um exemplo é o par servidão ambiental temporária - temporary conservation easement: partimos do termo em inglês conservation easement, equivalente funcional de servidão ambiental, ao qual acrescentamos o advérbio temporary. Casos como este também recebem uma nota explicativa que deverá constar no glossário almejado quando este for elaborado.

disapproval of a project. The purpose of an environmental impact report is to provide public agencies and the public in general with detailed information about the effect which a proposed project is likely to have on the environment; to list ways in which the significant effects of such a project might be minimized; and to indicate alternatives to such a project. (US040CACEQAG, Sc. 15362)

${ }^{15}$ EIS or Environmental Impact Statement means an environmental impact document prepared pursuant to the National Environmental Policy Act (NEPA). NEPA uses the term EIS in the place of the term EIR which is used in CEQA.

TradTerm, São Paulo, v. 32, dezembro/2018, p. 52-90

www.revistas.usp.br/tradterm 
Ademais, houve casos em que não encontramos um correspondente em inglês para o termo em português, provavelmente em razão das particularidades do processo de licenciamento ambiental de cada país. Ilustram tais casos termos como plano de controle ambiental e plano básico ambiental. Para o primeiro, embora não houvesse um termo equivalente, foi possível recorrer a um processo de equivalência literal, pois permitia manter as características do termo em português. Assim, criamos environmental control plan. Para o segundo termo, esse mesmo processo não seria possível, de modo que optamos por oferecer uma definição do termo: Plano básico ambiental - documento técnico requerido na etapa de licença de instalação que detalha as ações de mitigação dos impactos ambientais propostas no EIA/RIMA; Plano básico ambiental- a technical document required during the Installation License phase which specifies the impact mitigation actions proposed in the environmental impact study and environmental impact report.

Ao final dessa etapa, dada a complexidade de trabalhar a equivalência em sistemas jurídicos distintos e o quantitativo de termos levantados em português, conseguimos oferecer equivalentes em língua inglesa para 105 dos 371 termos do licenciamento ambiental. Dos 105 equivalentes oferecidos, apuramos 31 casos de equivalência parcial ou não-equivalência. Nesses casos, conforme relatado, utilizamos os recursos de expansão lexical, criação de neologismo ou uso de definição. Ademais, em aproximadamente 20 casos, a busca por equivalentes precisou extrapolar o corpus de estudo, recorrendo-se a páginas institucionais e a obras de referência, como glossários e dicionários terminológicos. A tabela abaixo resume esses quantitativos.

Tabela 5 - Resumo dos resultados encontrados

\begin{tabular}{l|c}
\hline ITEM & QUANTIDADE \\
\hline Termos encontrados em & 371 \\
português & 105 \\
Equivalentes oferecidos nesta & \\
pesquisa &
\end{tabular}

TradTerm, São Paulo, v. 32, dezembro/2018, p. 52-90

www.revistas.usp.br/tradterm 
Equivalência parcial ou não

equivalência

Equivalentes encontrados fora

do corpus

Fonte: elaborado pela autora

\section{Considerações finais}

A experiência da autora como analista de meio ambiente facilitou as etapas de identificação e seleção dos termos, o que prova ser necessário algum conhecimento a respeito do domínio especializado em estudo para a realização da pesquisa. Barros (2004: 192), ao descrever a metodologia do trabalho terminológico, corrobora tal crença ao afirmar que, para um terminólogo, um dos primeiros passos ao lançar-se em um projeto sobre um campo do conhecimento que não domine de modo aprofundado é a «familiarização com o objeto de estudo».

Contudo, mesmo com alguma experiência na área pesquisada, também foi necessário recorrer à leitura dos textos, em complementação aos contextos oferecidos pela ferramenta File view, para confirmar ou não a pertinência de alguns candidatos. Assim, neste estudo, a seleção dos termos não se baseou prioritariamente no critério estatístico de frequência de realização, mas na pertinência e representatividade das unidades terminológicas ao domínio.

Ao tomar por base a Teoria Comunicativa da Terminologia, foi possível registrar a existência de variação na terminologia do licenciamento ambiental, não se limitando a pesquisa à procura apenas dos termos preferenciais. Diferentes tipos de variação terminológica foram averiguados, conforme já apresentado (4. Metodologia e Resultados), com predomínio das reduções, como em impacto ambiental direto - impacto direto, e das siglas e acrônimos, como em Conselho Nacional do Meio Ambiente - CONAMA. 
Conforme aponta Cabré (1999b: 20, tradução nossa ${ }^{16}$ ), "para as diferentes disciplinas técnico-científicas, a terminologia é o conjunto das unidades de expressão e comunicação que permitem transferir o pensamento especializado", constituindo, assim, um meio de expressão e comunicação profissional, útil não apenas na comunicação entre especialistas, mas também entre estes e os ditos leigos ou semileigos. Tal crença motivou esta pesquisa de reconhecimento e compilação da terminologia do licenciamento ambiental, cujas etapas metodológicas foram aqui apresentadas.

A metodologia utilizada para a seleção e validação dos termos do licenciamento ambiental fundamentou-se no referencial teórico, no conhecimento da área de especialidade, obtido por meio da leitura de textos integrantes do corpus, na experiência da autora como analista da SEMA-MT, na organização de uma árvore de domínio e no uso dos fluxogramas desenhados para melhor compreensão do licenciamento ambiental.

Ao longo da execução das etapas metodológicas propostas, especialmente na etapa de validação dos candidatos a termo, constatamos que os fluxogramas apresentam pouca quantidade de texto, por vezes utilizando termos tidos como hiperônimos, ex.: "estudos ambientais", que podem representar uma série de outros termos de forma sintética, tais como estudo de impacto ambiental, estudo de viabilidade ambiental e estudo ambiental de sísmica. Tal característica é consequência do caráter ilustrativo e visual desses diagramas. Embora tragam, prioritariamente, termos mais gerais ou mais abrangentes, os fluxogramas se mostraram úteis para a melhor compreensão do domínio e para o processo de validação dos candidatos e eleição dos termos. Desta forma, o uso de tais diagramas pode ser vantajoso em estudos terminológicos de outras áreas de especialidade.

Quanto à organização sistemática dos termos, o uso do grafo como recurso de visualização possibilitou inserir todos os 371 termos eleitos em uma única ilustração, favorecendo a compreensão do domínio estudado a partir da relação entre os termos ali representados. Ademais, o grafo permitiu identificar, na ilustração, os diferentes grupos que compõem a terminologia

\footnotetext{
${ }^{16}$ Para las diferentes disciplinas científico-técnicas, la terminología es el conjunto de las unidades de expresión y comunicación que permiten transferir el pensamiento especializado. Cabré (1999b: 20).
} 
do licenciamento ambiental, tais como documentos, licenças e tipos de licenciamento, conforme a árvore de domínio.

Quanto à questão da equivalência, o grande número de casos em que se precisou recorrer a materiais fora dos corpora para se oferecer um equivalente, ou mesmo os casos em que não foi possível oferecer um equivalente funcional podem ser consequência do caráter diferenciado da atividade de licenciamento ambiental em comparação ao licenciamento norte-americano até mesmo aos demais licenciamentos ambientais que ocorrem no mundo, visto que apenas o Brasil divide o processo de licenciamento ambiental em três fases. Embora existam elementos comuns, trazidos da política norte-americana ou de políticas internacionais, tais como a avaliação de impacto ambiental (environmental impact assessment), a falta de equivalentes pode indicar que o licenciamento ambiental brasileiro traz elementos e conhecimentos presentes apenas no Brasil.

A pesquisa prossegue em prol de um objetivo maior: a elaboração do glossário português-inglês do licenciamento ambiental por meio do qual almejamos contribuir para a melhoria da comunicação entre os profissionais do meio ambiente e o público estrangeiro, impactando positivamente 0 processo de licenciamento e a proteção ambiental. Esperamos, por fim, que o estudo relatado possa servir não apenas a seu objetivo, mas que também ofereça alguma contribuição à comunidade acadêmica, em especial àqueles que trilharão passos semelhantes aos nossos. 


\section{Referências bibliográficas}

ANTHONY, L. AntConc (Version 3.4.3) [Windows]. Tokyo, Japan: Waseda University. 2014. Disponível em:

<http://www.antlab.sci.waseda.ac.jp/>. Acesso em: 15 dez. 2014.

BarRos, L. A. Curso básico de Terminologia. São Paulo: Edusp. 2004.

BeVILACQUA, C. R. "Investigación sistemática en terminología”. In BARITÉ, M.; Álvarez, S. (org.). Teoría y praxis en Terminología. Montevideo: UdelaR. 2015. (no prelo)

BRASIL. Lei n. 6.938, de 31 de agosto de 1981. Dispõe sobre a Política Nacional do Meio Ambiente, seus fins e mecanismos de formulação e aplicação, e dá outras providências. 1981. Disponível em: <http://www.planalto.gov.br/ccivil_03/leis/16938.htm>. Acesso em: 20 ago. 2013.

BrasIL. Ministério do Meio Ambiente. Conselho Nacional do Meio Ambiente. Resolução n. 001, de 23 de janeiro de 1986. Disponível em: <http://www.mma.gov.br/port/conama/res/res86/res0186.html>. Acesso em: 20 ago. 2013

BrasIL. Ministério do Meio Ambiente. Conselho Nacional do Meio Ambiente. Resolução n. 237, de 19 de dezembro de 1997. Disponível em: <http://www.mma.gov.br/port/conama/res/res97/res23797.htmll. Acesso em: 20 ago. 2013.

BRASIL. Lei n. 9.605, de 12 de fevereiro de 1998. Dispõe sobre as sanções penais e administrativas derivadas de condutas e atividades lesivas ao meio ambiente, e dá outras providências. 1998. Disponível em: <http://www.planalto.gov.br/ccivil_03/leis/19605.htm>. Acesso em: 20 ago. 2013.

BrASIL. Ministério do Meio Ambiente. Conselho Nacional do Meio Ambiente. Resolução n. 350, de 06 de julho de 2004. Disponível em: <http://www.mma.gov.br/port/conama/legiabre.cfm?codlegi=451>.

BrasIL. Tribunal de Contas da União. Cartilha de Licenciamento Ambiental, 2.ed. Brasília: TCU. 2007.

BrASIL. Ministério do Meio Ambiente. Conselho Nacional do Meio Ambiente. Resolução n. 458, de 16 de julho de 2013. Disponível em: <http://www.mma.gov.br/port/conama/legiabre.cfm?codlegi=696>.

CABRÉ, M. T. La Terminologia: Representación y Comunicación. Barcelona, IULA. 1999a. 
CABRÉ, M. T. Terminology: theory, methods and applications. Edited by Juan C. Sager; translated by Janet Ann De Cesaris. Amsterdam: John Benjamin Publishing Co. 1999b.

California environmental Protection Agency. History of the California Environmental Protection Agency. Disponível em: <http://www.calepa.ca.gov/ About/History01/\#sthash.ZGz5W7FI.dpuf>. Acesso em: 23 set. 2015.

CaO, D. Translating Law. Clevedon/Buffalo/Toronto: Multilingual Matters. 2007.

ChANUT, M. E. P. A noção de equivalência e a sua especificidade na tradução especializada. TradTerm, São Paulo, v. 19, p. 43-70, 2012. Disponível em: <http://tradterm.vitis.uspnet.usp.br>. Acesso em: 15 fev. 2015.

ChICHORRo, C. L. M. Terminologia do Licenciamento Ambiental em português e inglês. Patrícia Chittoni Ramos Reuillard. Porto Alegre: UFRS, 2016. 171 p. Dissertação (Mestrado em Teorias Linguísticas do Léxico) Universidade Federal do Rio Grande do Sul. 2016.

Finatto, M. J. B. Terminologia e Lingüística de Corpus: da Perspectiva Enunciativa aos Novos Enfoques do Texto Técnico-científico. Letras de Hoje, Porto Alegre, v. 39, n. 4, dezembro, 2004. p. 97-106. Disponível em:

<http://www.ufrgs.br/textecc/textquim/arquivos/Terminologia_e_lin guistica_de_corpus.pdf >. Acesso em: 23 nov. 2018.

FIESP - FEderaçÃo dAS IndústRIAS do Estado de SÃo PAULO -Licenciamento ambiental e as micro e pequenas empresas, 1. São Paulo: FIESP. 2006.

GARZONE, G. Legal translation and functionalist approaches: a contradiction in terms? Géneve: Actes, 2000.

GÉmAR, J. C. Les enjeux de la traduction juridique. Principes et nuances. Astti Seminar: Équivalences. $1998 . \quad$ Disponível em: <www.tradulex.com/Bern1998/Gemar.pdf>. Acesso em: 12 dez. 2014.

GudumaC, I. Dificuldades de traduzir textos jurídicos: um enfoque funcionalista. 2011. 106f. Dissertação (Mestrado em estudos Ingleses e Americanos). - Faculdade de Letras, Universidade de Lisboa, Lisboa, 2011.

KRIEger, M. G.; MaCIeL, A. M. B. Temas de Terminologia. Porto Alegre/São Paulo: Editora da Universidade/UFRGS/Humanitas/USP. 2001.

KRIEger, M. G.; Finatto, M. J. B. Introdução à Terminologia: teoria e prática. São Paulo: Contexto. 2004.

LOH, S. Listas de stopwords - stoplist (portugues, ingles, espanhol). Blog do Stanley Loh. 2008. Disponível em: 
<http://miningtext.blogspot.com.br/search?q=stoplist>. Acesso em: 11 ago. 2014.

MACIEL, A. M. B. "Reflexão sobre a pesquisa terminológica em corpus". Encontro Nacional da ANPOLL 21, Disponível em: <http://www.ufrgs.br/termisul/biblioteca/artigos/artigos.php>. Acesso em: 28 out. 2014.

NORD, C. Translating as a purposeful activity: functionalist approaches explained. Manchester: St. Jerome, 1996.

Pavel, S.; Nolet, D. Manual de Terminologia. Tradução de Enilde L. de J. Faulstich. Disponível em: <www. fititf.org/download/presport.pdf>. Acesso em: 25 jul. 2014.

SAGER, J. C. A practical course in terminology processing. Amsterdam/Philadelphia: John Benjamins Publishing Co.1990.

"SAL", in Dici Dicionário da Língua Portuguesa [em linha], 2009-2018, Disponível em: <https://www.dicio.com.br/sal/>. Acesso em: 23nov. 2018.

ŠARČEVIĆ, S. New approach to legal translation. London: Kluwer Law International, 1997.

SARDInHA, A. B. Linguística de Corpus. Barueri, SP: Manole. 2004.

ScHütZ, R. O inglês como língua internacional. English Made in Brazil. jul. 2010. Disponível em: <http://www.sk.com.br/sk-ingl.html>. Acesso em: 11 nov. 2015.

SEBRAE - SeRVIço Brasileeiro de Apolo Às Micro e Pequenas EMPRESAS -: Licenciamento ambiental. Cuiabá: Sebrae. 2012.

UnITED STATES. Executive Office of the President. Council on Environmental Quality. A citizen's guide to NEPA: having your voice heard. 2007. Disponível em:

<https://ceq.doe.gov/nepa/Citizens_Guide_Dec07.pdf>. Acesso em: 29 abr. 2015.

Recebido em: $11 / 07 / 2018$

Aceito em: 10/12/2018

Publicado em dezembro de 2018 